\title{
Innovative Analysis of Service-Learning Effects in Physical Education: A Mixed-Methods Approach
}

\author{
Carlos Capella-Peris \\ Universitat Jaume I and National Institutes of Health \\ Jesús Gil-Gómez and Òscar Chiva-Bartoll \\ Universitat Jaume I
}

\begin{abstract}
Purpose: To compare the development of teaching competency in preservice teachers of physical education $(n=96)$ through two different modalities of intervention from the same service-learning program. The preservice teachers provided a direct service to children with motor functional diversity, promoting their motor skills and counteracting their lack of social attention. Method: The topic was approached using mixed methods with methodological triangulation. Quantitative evidence was gathered through a quasiexperimental design of two nonequivalent experimental groups implementing the following instrument: the Teaching Competency while performing Motor Skills and Body Language Games Rubric. Meanwhile, qualitative analysis was undertaken by elaborating upon 12 life histories of multiple crossed stories. Results: The quantitative results provided significant evidence regarding the academic effect of service-learning on preservice teachers, while the qualitative interpretation complemented this view, reflecting on how this learning was developed. Discussion/Conclusion: The authors provided the original findings of the service-learning effects on the teaching competency of preservice teachers as well as the promotion of additional academic and social learning.
\end{abstract}

Keywords: teaching competency, preservice teachers, rubric, motor functional diversity, life histories

The competence-based approach to train preservice teachers (PTs) promotes the implementation of active and experiential methodologies, allowing students to apply learning in real conditions (Chambers \& Lavery, 2012). In accordance with this view, servicelearning (SL) is a teaching methodology that seeks to develop academic competencies and increase reflection while providing a community service to meet social needs (Yorio \& Ye, 2012). Moreover, SL has the potential to promote social justice (Jones \& Kiser, 2014) and enhance students' critical thinking (Mitchell, 2008).

Service-learning is based on John Dewey's experiential learning theory (Dewey, 1938). This theoretical framework states that everything occurs within a social environment. For this reason, learning is socially constructed and based on experiences. According to this, experiential learning supports that knowledge should be organized in real-life experiences to provide context for information. The connection between SL and Dewey's proposal has been previously exposed in physical education (PE) (Domangue \& Carson, 2008).

Previous research on SL revealed improvements in attitudes toward self and attitudes toward school and learning, civic engagement, social skills, and academic performance (White, 2001). When training PTs, SL produced personal, social, and professional development; emotional engagement and cognitive readiness with the community; and increased evaluation skills (Chambers \&

Capella-Peris, Gil-Gómez, and Chiva-Bartoll are with the Department of Education and Didactics of Specific Subjects, Universitat Jaume I, Castellón, Spain. CapellaPeris is also with Neuromuscular Symptoms Unit, Tissue Injury Branch, National Institute of Nursing Research, National Institutes of Health, Rockville, MD, USA. Capella-Peris (capellac@uji.es and carlos.capellaperis@nih.gov) is corresponding author.
Lavery, 2012; Seban, 2013). On the other hand, one of the characteristics that defines SL in PE, in contrast with other fields, is that SL involves physical interaction and active participation (Carson \& Raguse, 2014; Cervantes \& Meaney, 2013). When it comes to training PTs in PE, SL has increased their knowledge of the curriculum, their perceived competency as teachers, and their teaching strategies (Galvan, Meaney, \& Gray, 2018; LaMaster, 2001; Meaney, Griffin, \& Bohler, 2009). In addition, SL stands as a favorable opportunity to develop PE competencies, combining theory and practice in the same activity (Wilkinson, Harvey, Bloom, Joober, \& Grizenko, 2013).

However, new research is needed to analyze the wide variety of differentiating aspects between SL projects, referring, for example, to intensity and duration, type of service, tasks developed, and so forth, as indicated in the meta-analyses in several knowledge areas (Celio, Durlak, \& Dymnicki, 2011; Conway, Amel, \& Gerwien, 2009; Yorio \& Ye, 2012). Along this line, a significant contribution of our research design is based on a comparison of two modalities of intervention from the same SL program, as no similar comparisons have been found in a literature search of previous studies. The main difference between the two modalities lies in the duration and intensity of the service provided. Despite several recommendations previously provided (National Youth Leadership Council, 2004), there are no established parameters of duration and intensity of SL programs. Previous reviews analyzed implementations of SL programs in PE that lasted from 5 to $20 \mathrm{hr}$ over 4-12 weeks (Cervantes \& Meaney, 2013). However, the comparison of their effects is skewed by a large number of individual differences, which makes it difficult to interpret the duration and intensity variables. Therefore, we try to shed light on this issue by comparing two intervention modalities of the same SL program with different and well-defined duration and intensity parameters. 
Following a similar approach to previous works, we analyzed the effects of SL in PE (Domangue \& Carson, 2008; Galvan \& Parker, 2011; Galvan et al., 2018; Miller, 2012; Pechak \& Thompson, 2011; Ward, Pellett, \& Perez, 2017; Webster, Nesbitt, Lee, \& Egan, 2017; Whitley, Walsh, Hayden, \& Gould, 2017; Wilkinson et al., 2013). However, while other research focused on the personal, civic, or social effects of this methodology (Domangue \& Carson, 2008; Meaney, Bohler, Kopf, Hernandez, \& Scott, 2008; Miller, 2012; Ward et al., 2017; Whitley et al., 2017), the main emphasis of this research is the analysis of the academic progress of PTs. Specifically, we assessed the teaching competency (TC) when designing and applying motor skills and body language games. This perspective has great value in the development and promotion of SL as a pedagogical methodology in PE. First, it demonstrates the academic contribution of this approach, refuting those who might doubt its benefits in this sense, and second, it promotes balance in SL research topics in PE, as very few studies analyzed the academic effect of SL in teaching PE.

Thus, the main goal of this study is to analyze and compare two different modalities of intervention from the same SL program, thereby producing new and interesting findings regarding the application of this methodology in $\mathrm{PE}$, and, specifically, to promote the TC of PTs.

Moreover, the use of mixed methods is an original approach in these kinds of studies (Cervantes \& Meaney, 2013), allowing us to analyze the research question from both objective and subjective perspectives. In addition, the implementation of our design differs from previous works (Domangue \& Carson, 2008; Miller, 2012), as it performs a data transformation and combines three types of results in the discussion (Camerino, Castañer, \& Anguera, 2012; Creswell \& Plano Clark, 2007).

\section{Materials and Methods}

\section{Research Settings}

The study was performed in the Early Childhood Education degree of Universitat Jaume I in Spain. The PTs from a PE course had to organize, apply, and manage several sessions of motor skills and body language games to serve a total number of 150 children with motor functional diversity. This condition was due to autism spectrum disorder, down syndrome, cerebral palsy, attention deficit and hyperactivity disorder, and Rett's syndrome. The term motor functional diversity is an umbrella concept used to describe any alteration of motor behavior, such as repetitive movements or hyperactivity; problems with balance or coordination; poor muscle control, reflexes and posture; hypotonia; delayed development; and other alterations of motor function. This term proposes a shift toward nonnegative, nondisparaging, and nonpatronizing terms, aiming to replace the ones with pejorative semantics, such as special needs, disability, impairment, and handicap. The goal of the SL program was to stimulate the motor skills of these children and to relieve their lack of social attention. The sessions were meant to foster both academic learning and TC of PTs in PE.

The SL program was particularly applied to the course Fundamentals of Body Language: Motor Games in Early Childhood Education. According to the curriculum and course syllabus, this subject aims to develop the following competencies and learning outcomes in PTs: arrange educational activities based on the progressive integration of PTs (e.g., adaptation, cohesion, consolidation, etc.), promote body language to achieve better communication and to develop social skills, implement symbolic and role-playing games to promote knowledge of social issues, create suitable motor skills proposals for several age groups during the childhood stage, develop habits of personal autonomy and compliance with coexistence rules, select suitable materials and locations to perform motor skills games with children, use games as a main teaching resource and design learning activities based on ludic terms, apply a wide range of body language proposals, design motor skills and body language activities within the curriculum for the childhood stage, promote values through motor skills games and body language activities to children (e.g., cooperation, solidarity, respect, etc.), develop movement and body language activities that are appropriate to children's needs, implement motor skills games that effectively aid the attainment of educational goals, and use movement as a tool for learning and socialization and understand its relevance during the childhood stage.

The SL intervention modalities matched with the two groups under study, Experimental Group I (EGI) and Experimental Group II (EGII). Both groups worked jointly on the design and implementation of the game sessions, although there were important differences in their dedication in terms of duration and intensity. Although the participation of the EGI PTs involved 30 sessions, with an average duration of $1 \mathrm{hr}$ for each session, the EGII members participated only in nine of those sessions. The amount of time dedicated for EGI to prepare and perform the game sessions was estimated at $150 \mathrm{hr}(100 \%$ of the course time). On the other hand, the members of EGII limited their dedication to $45 \mathrm{hr}$ (30\% of the course time). In terms of intensity of the SL program, both groups applied a weekly schedule. However, although PTs from EGI participated throughout the academic year, which involved a period of 9 months, the intervention for EGII members was restricted to 2 months. Finally, although there were 68 PTs in the EGII, the EGI was composed of only by 28 members, demanding a higher workload to complete their tasks. These differences in the service implementation suggested that the impact of the SL program on the EGI PTs would be higher due to their larger exposure.

To develop the course content, the PTs from EGI completed 10 specific training sessions before starting the SL activities. During those sessions, the PTs received information referring to SL methodology, cooperative learning strategies, and characteristics of the children involved. In addition, guidelines for how to perform sessions on motor skills and body language games, as well as examples to learn how to apply those guidelines, were provided as follows: adjust the activities to the specific characteristics of the participating children, develop games with an adequate number of players considering the number of teachers conducting the game, maximize the time of motor involvement during the sessions, optimize the organization of the teachers by distributing responsibilities, maximize the use of available materials and facilities, apply games to develop basic motor skills (i.e., walking, running, jumping, balance, catching, receiving, throwing, hitting, and kicking), apply games to develop body language skills (e.g., symbolism, communication, role representation, relaxation), provide adequate activities to the educational context for each group of children, use rewards and incentives to keep the students highly motivated to participate, use innovative and affordable materials (e.g., wool, toilet paper, balloons, bottles, cardboard, newspapers, chalk, wax, rubber bands, ropes), encourage full participation of the children by avoiding games that remove the participants while playing, avoid queues and reduce waiting time during games, use simple and divisible group structures during the sessions, and apply a high standard of security for all activities.

On the other hand, PTs from EGII started the academic year following the standard schedule. They worked with the professor to develop course content until the SL program was set. Lessons were 
performed through classic lectures using traditional methodologies. When the SL program was set, each PT selected a time for involvement from the available dates. To start their participation in the SL activities, the PTs were informed about the specific characteristics of the program from their peers in EGI. Both groups worked together in developing and performing the sessions on motor skills and body language games with the children. During those sessions, the EGII members applied knowledge acquired through lectures with the professor. Once they finished their commitment with the SL program, PTs from EGII kept working with the professor in the classroom, as they had previously, until the end of the academic year.

\section{Variables}

In this study, the independent variable was the SL program in both intervention modalities, whereas the dependent variable referred to the TC of the PTs in the PE area.

\section{Design and Data Collection}

This study combined quantitative and qualitative research methodologies; its design was located within the mixed-method approaches, and it used methodological triangulation. The use of these designs in PE and sports has been effectively supported (Camerino et al., 2012).

The quantitative evidence was gathered through a quasiexperimental design using two nonequivalent experimental groups, performing pre- and posttest measurements. To assess the dependent variable the following instrument was used: the Teaching Competency while performing Motor Skills and Body Language Games Rubric (TC/MSBLG-R) (Capella-Peris, Gil-Gómez, \& Chiva-Bartoll, 2018). This instrument specifically measures the TC of teachers when displaying game sessions focused on motor and body language skills. The reliability of this tool is excellent $(\alpha>.9)$, showing a value of $\alpha=.955$ on Cronbach's alpha test. Besides, its nomological validity is ensured based on the relationships with other constructs in accordance with a relevant broader theory (Cronbach \& Meehl, 1955). The research team applied this tool observationally on the PTs when they were providing the service sessions. To analyze the quantitative data, the following tests were applied. First, Cronbach's alpha test was used to analyze the reliability of the quantitative data. Later, Levene's test was applied to verify the initial equivalence between groups. Then, a paired sample $t$ test was used to assess the changes between the preand posttest measurements for both groups. Finally, Levene's test was applied once again to compare the posttest measurements between groups. In addition, Pearson's test was used to explore the correlations among the categories of the TC/MSBLG-R instrument. All of the tests were applied on two levels of analysis: globally and by categories.

The qualitative section was undertaken using biographical methods, elaborating upon 12 life histories of multiple crossed stories. Thus, the individual and collective effects on the TC of the PTs were analyzed. This method allows the knowledge, experiences, feelings, beliefs, and values shared in a learning community to be investigated more deeply, as previously demonstrated in PE teacher education (Sparkes, Templin, \& Schempp, 1993). As we expected to produce a stronger impact on the EGI PTs, due to their greater exposure to the SL program, all of the members from this group were interviewed to elaborate upon their life histories. From all of the interviews collected, four were selected to apply the qualitative analysis using quota sampling, considering the representativeness of the PTs. Eight additional interviews were selected applying snowball sampling, regarding the suggestions of the PTs from quota sampling. Following common guidelines to perform life histories (Hernández, Sancho, \& Rivas, 2011; Pamphilon, 1999), the PTs were requested to prepare themselves as follows: interviews would be open, so there were no questions decided beforehand, although questions could be asked to retrieve or expand comments about interesting issues; PTs should explain their experience as telling a story to a friend; they could use any support file to illustrate the story (guides, reflections, comments, reminders, reports, etc.); the story should be focused on academic and personal impacts as the main objectives; contextual and additional information should also be provided (suggestions, opinions, interpretations, etc.); and all important information should be organized in chronological order, from the very beginning until the end of the SL program. Furthermore, after displaying those instructions, any additional doubt regarding the interviews was resolved. The interviews were analyzed following a thematic analysis from an illustrative approach (Demazière \& Dubar, 1997). Thematic areas used to perform the qualitative analysis were defined by the TC/MSBLG-R instrument (Capella-Peris et al., 2018), allowing researchers to compare the quantitative and qualitative results of the discussion. In addition, the researchers' interpretations were added while constructing life histories from the biographical stories, as this was the main difference between both qualitative approaches (Denzin, 1989).

Finally, we transformed the qualitative data into quantitative results (Gil-Gómez, Chiva-Bartoll, \& Marti-Puig, 2015). Although the qualitative study assesses the importance and depth of the comments from the PTs, the data transformation shows the frequency of citations for each category and aspect. This quantitative analysis of the interviews provides a complementary view of the discourse, offering a new perspective of the SL effects.

\section{Research Question and Hypothesis}

The main question needing a response in this research is How will the SL program affect the experiences and learnings of PTs related to their $T C$ in $P E$ ? Furthermore, three specific hypotheses were also tested. $\mathrm{H}_{1}$ : The $\mathrm{SL}$ program will produce a significant improvement $(p<.05)$ in the TC/MSBLG-R results for the EGI, $\mathrm{H}_{2}$ : The $\mathrm{SL}$ program will produce a significant improvement $(p<.05)$ in the TC/MSBLG-R results for the EGII, and $\mathrm{H}_{3}$ : The SL program will produce a significant improvement $(p<.05)$ in the TC/MSBLG-R results for the EGI compared with the EGII.

\section{Sample Description and Selection}

The study used an incidental-type nonprobabilistic sample, with the sample selection matched to the class group. The total sample was 96 PTs: $29.2 \%(n=28)$ in the EGI and $70.8 \%(n=68)$ in the EGII. The mean age of all of the participants was $20.96( \pm 3.03)$ years. The sample comprised $95(99 \%)$ females and one (1\%) male. This gender distribution has precedent in the previous research on SL in early childhood education (Lake, Al Otaiba, \& Guidry, 2010; Lake \& Jones, 2008), as females continue to be the trend for teaching in this field (Domangue \& Carson, 2008). Additional information regarding the PTs' background is provided to disclose the social context of this project. In terms of their experience as volunteers, 21 PTs $(21.9 \%)$ had previously collaborated in volunteer/not-for-profit activities, whereas 75 PTs $(78.1 \%)$ had never participated in such 
tasks. Referring to their education, 48 PTs $(50 \%)$ had completed secondary education, $46(47.9 \%)$ possessed an associate degree, and two $(2.1 \%)$ had already completed a bachelor's degree. In terms of their teaching experience, 44 PTs $(45.8 \%)$ had no previous experience, whereas $52(54.2 \%)$ had already performed some teaching activities, most of them while completing their associate/bachelor's degree. Finally, referring to their experience in the field of physical activity and sports, 15 PTs $(15.6 \%)$ were not participating in any of those activities regularly, $63(65.6 \%)$ were practicing in sports and physical activities on a regular basis, and 18 (18.8\%) were usually involved in teaching tasks related to physical activity and sports.

\section{Results}

\section{Quantitative Analysis}

This section shows the results of the statistical tests performed throughout the quantitative study. The IBM SPSS Statistics for Windows v.24.0 software package (IBM Corp., Armonk, NY) was used in this analysis.

First of all, a reliability test was performed. A value of $\alpha=.941$ was obtained for Cronbach's alpha test, showing excellent internal consistency. The reliability results for the second-order factors (categories) were acceptable $(.7 \leq \alpha<.8)$ for two cases, good $(.8 \leq \alpha<.9)$ for six cases, and excellent $(.9 \leq \alpha<1)$ for two cases. Second, the initial equivalence was verified. A value of $t(78)=$ $0.407, p>.05$ was obtained for Levene's test; therefore, the initial samples were considered equal. Then, a pre-posttest comparison was performed. The values obtained when applying the paired sample $t$ test were $t(39)=5.618, p<.01$ for the EGI and $t(39)=$ $5.905, p<.01$ for the EGII. Hence, there were significant differences between the pre- and posttest measures in both cases. This situation was also present in the comparison by categories, where significant differences $(p<.05)$ between the pre- and posttest measures were found for the categories of teacher organization and game adjustment, time organization and game variety, and body language games and assessment for both groups; equipment, originality, and ludic value, social features, and global features of motor skills games for EGI; and game presentation and rule compliance and space organization for EGII. Later, a post-posttest comparison was completed. A value of $t(78)=0.143, p>.05$ was obtained for Levene's test. Therefore, despite the slightly higher results in EGI $(x=2.976)$ compared with EGII $(x=2.964)$, there were no significant differences in the posttest results between both groups. This situation was reflected in the comparison by categories, where the two groups obtained similar results without significant differences. Finally, correlation tests were performed. Pearson's test found 40 significant records out of 45 , all of which were positive and had a significance level of $p<.01$. The degrees of correlation were perfect $\left(r_{\mathrm{p}}=1\right)$ for one case, high $\left(.6 \leq r_{\mathrm{p}}<.8\right)$ for one case, moderate $(.4 \leq$ $\left.r_{\mathrm{p}}<.6\right)$ for 24 cases, and low $\left(.2 \leq r_{\mathrm{p}}<.4\right)$ for 14 cases.

\section{Qualitative Analysis}

Qualitative analysis was conducted through 12 life histories of multiple crossed stories. The information recorded was analyzed following the categories and aspects of the TC/MSBLG-R. Following the accepted recommendations for qualitative analysis, a double procedure was applied, from inductive to deductive, and back again (Flick, 2014). The Nvivo qualitative data analysis software v.10 (QSR International Pty Ltd., Doncaster, Victoria, Australia) was used in this analysis.
All extracts used in this qualitative analysis included the category and aspect name, researcher interpretation, textual transcript of the PTs' comments, and reference code. This section offers extracts from the most representative elements as examples. The selection of these quotations is related to its importance and depth to highlight the PTs' experience in each case.

- Teacher organization and game adjustment-period: the gradual increase of difficulty shows that the PTs integrated this basic concept for any teaching-learning process. This learning was reinforced through the enhancement of the PTs' confidence due to their better knowledge of the children's capacities and their improved performance as teachers.

"First of all, we thought . . we are going to do activities where they do not have to move much, something easy. .. . But now, since they have improved, we ask them to put more effort into activities." (C05, Ref. 3)

- Game presentation and rule compliance-control of compliance rules: this PT corrected an inappropriate behavior from children not only to maintain discipline, but also to earn respect. Her conduct is remarkably meritorious because the disagreement among PTs makes it difficult to show such attitudes reproving some actions from the players. The depth of her reflection is also emphasized, thanks to a convincing explanation about the motivation for her action.

"At the beginning, they did not listen to us; we told them to not do that, and they kept ignoring us, so I took the ball, and I said. . . 'You should go to take the bags because we have finished playing today!' My classmates told me... 'You are harsh!' And I said ... otherwise, they are going to make fun of us! This is how they will realize they are playing the wrong way. If they are doing something wrong and you let them keep playing, they will carry on playing the wrong way." (C12, Ref. 2)

- Equipment, originality, and ludic value-innovation and originality: a new game, where players had to characterize older peers, leaves no doubts about the creative minds of the PTs. The children's creativity was also encouraged during this game. Moreover, the cooperative dynamic allowed the PTs to address social issues while playing.

"We made a super cool game, it was . . like we were swimming, and, in the middle, there were some swim wear, bathing suits, bathing caps, bathing goggles, towels ... and the youngest children had to dress up two of their peers. They had to put clothes on them to play." (C03, Ref. 1)

- Time organization and game variety-time optimization/ adaptation: the PTs avoided wasting time during the sessions. By reducing time-outs, they maximized the time for practice and increased the children's active participation. This learning outcome has enormous value in PE because, as students must move from the classroom to the gym, these courses usually receive less time for practice.

"We did not waste time between games and also allowed less time for snacks ... the most important thing was to play games and to develop their motor skills as much as possible." (C09, Ref. 2)

- Body language games and assessment-symbolism: this activity showed how to provide lots of meaning to games. Thanks to this original proposal, the PTs enhanced motor skills in the children in a highly engaging and motivating way. This ability 


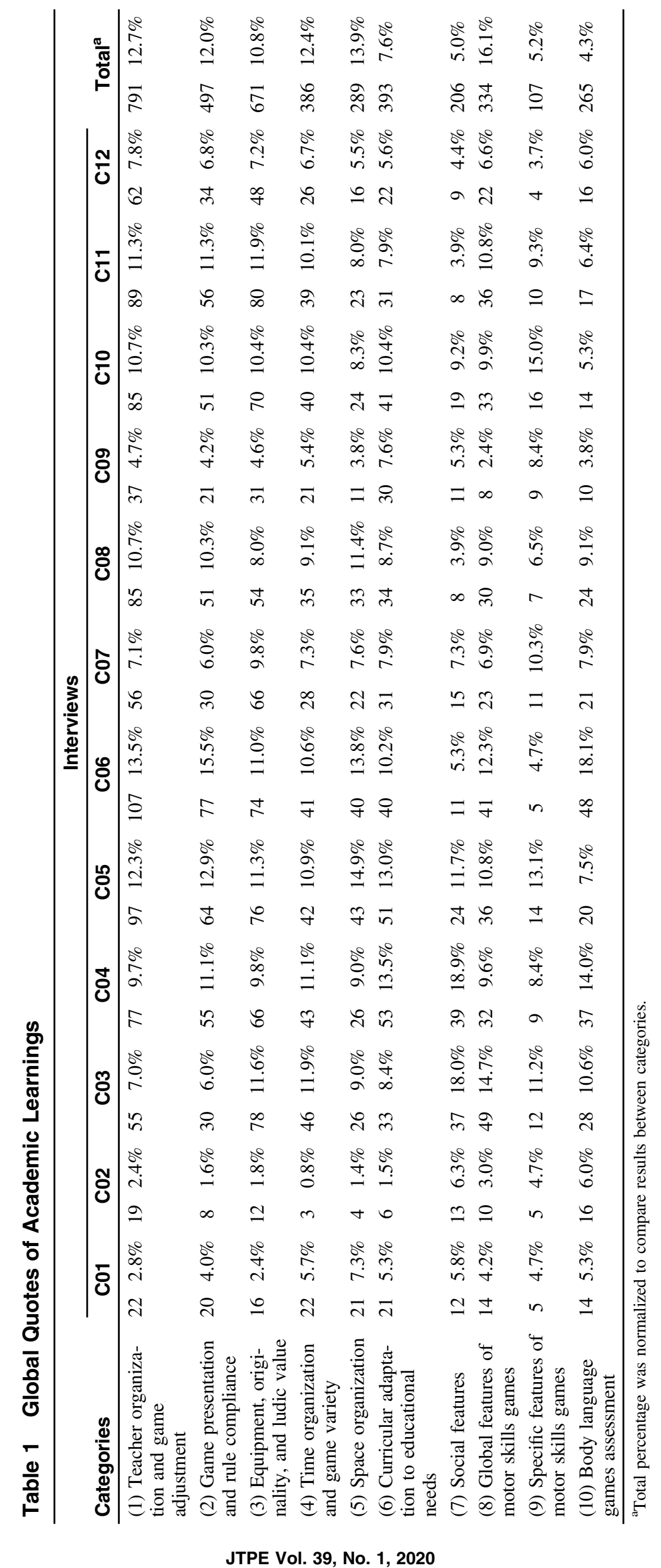


Table 2 Body Language Games and Assessment Quotes

\begin{tabular}{|c|c|c|c|c|c|c|c|c|c|c|c|c|c|c|c|c|c|c|c|c|c|c|c|c|}
\hline \multirow[b]{2}{*}{ Aspects } & \multicolumn{22}{|c|}{ Interview } & \multirow{2}{*}{\multicolumn{2}{|c|}{ Total }} \\
\hline & & $\mathrm{C} 01$ & $\mathrm{CO2}$ & & $\mathrm{CO3}$ & & C04 & & C05 & & C06 & & C07 & & C08 & C09 & & C10 & & C11 & & C12 & & \\
\hline $\begin{array}{l}\text { (10a) Expression } \\
\text { activities }\end{array}$ & 2 & $3 \%$ & $34.2 \%$ & 15 & $21.1 \%$ & 10 & $14.1 \%$ & 5 & $7.0 \%$ & 7 & $9.9 \%$ & 7 & $9.9 \%$ & 6 & $8.5 \%$ & $22.8 \%$ & 3 & $4.2 \%$ & 6 & $8.5 \%$ & 5 & $7.0 \%$ & 71 & $26.8 \%$ \\
\hline $\begin{array}{l}\text { (10b) Corporal } \\
\text { communication }\end{array}$ & 2 & $13.3 \%$ & $00.0 \%$ & 1 & $6.7 \%$ & 1 & $6.7 \%$ & 1 & $6.7 \%$ & 3 & $20.0 \%$ & 1 & $6.7 \%$ & 1 & $6.7 \%$ & $16.7 \%$ & 1 & $6.7 \%$ & 1 & $6.7 \%$ & & $13.3 \%$ & 15 & $5.7 \%$ \\
\hline $\begin{array}{l}\text { (10c) Roles } \\
\text { representation }\end{array}$ & 0 & $0.0 \%$ & $29.1 \%$ & 1 & $4.5 \%$ & 2 & $9.1 \%$ & 1 & $4.5 \%$ & 5 & $22.7 \%$ & 2 & $9.1 \%$ & 2 & $9.1 \%$ & $14.5 \%$ & 1 & $4.5 \%$ & 3 & $13.6 \%$ & 2 & $9.1 \%$ & 22 & $8.3 \%$ \\
\hline $\begin{array}{l}(10 d) \\
\text { Symbolism }\end{array}$ & 2 & $7.1 \%$ & $27.1 \%$ & 1 & $3.6 \%$ & 3 & $10.7 \%$ & 2 & $7.1 \%$ & 5 & $17.9 \%$ & 4 & $14.3 \%$ & 2 & $7.1 \%$ & $13.6 \%$ & 1 & $3.6 \%$ & & $14.3 \%$ & 1 & $3.6 \%$ & 28 & $10.6 \%$ \\
\hline $\begin{array}{l}\text { (10e) Represen- } \\
\text { tation (visual } \\
\text { description) }\end{array}$ & 2 & $7.4 \%$ & $27.4 \%$ & 4 & $14.8 \%$ & 1 & $3.7 \%$ & 3 & $11.1 \%$ & 5 & $18.5 \%$ & 0 & $0.0 \%$ & 2 & $7.4 \%$ & $00.0 \%$ & 3 & $11.1 \%$ & 2 & $7.4 \%$ & 3 & $11.1 \%$ & 27 & $10.2 \%$ \\
\hline $\begin{array}{l}\text { (10f) Activities } \\
\text { assessment }\end{array}$ & 6 & $5.9 \%$ & $76.9 \%$ & 6 & $5.9 \%$ & 20 & $19.6 \%$ & 8 & $7.8 \%$ & 23 & $22.5 \%$ & 7 & $6.9 \%$ & 11 & $10.8 \%$ & $54.9 \%$ & 5 & $4.9 \%$ & 1 & $1.0 \%$ & 3 & $2.9 \%$ & 102 & $38.5 \%$ \\
\hline
\end{tabular}

Table 3 Quotes of Academic Learnings on C04 Interview

\begin{tabular}{|c|c|c|c|c|c|c|c|c|c|c|c|c|c|c|}
\hline \multirow{3}{*}{$\begin{array}{l}\text { Categories } \\
\text { (1) Teacher organization and game adjustment }\end{array}$} & \multicolumn{12}{|c|}{ Aspects } & \multirow{2}{*}{\multicolumn{2}{|c|}{ Total $^{\mathbf{a}}$}} \\
\hline & \multicolumn{2}{|r|}{ (a) } & \multicolumn{2}{|r|}{ (b) } & \multicolumn{2}{|r|}{ (c) } & \multicolumn{2}{|r|}{ (d) } & \multicolumn{2}{|r|}{ (e) } & \multicolumn{2}{|r|}{ (f) } & & \\
\hline & 13 & $16.9 \%$ & 6 & $7.8 \%$ & 17 & $22.1 \%$ & 6 & $7.8 \%$ & 20 & $26.0 \%$ & 15 & $19.5 \%$ & 77 & $11.5 \%$ \\
\hline (2) Game presentation and rule compliance & 17 & $30.9 \%$ & 16 & $29.1 \%$ & 18 & $32.7 \%$ & 4 & $7.3 \%$ & & & & & 55 & $12.3 \%$ \\
\hline (3) Equipment, originality, and ludic value & 11 & $16.7 \%$ & 17 & $25.8 \%$ & 5 & $7.6 \%$ & 9 & $13.6 \%$ & 13 & $19.7 \%$ & 11 & $16.7 \%$ & 66 & $9.8 \%$ \\
\hline (4) Time organization and game variety & 6 & $14.0 \%$ & 11 & $25.6 \%$ & 26 & $60.5 \%$ & & & & & & & 43 & $12.8 \%$ \\
\hline (5) Space organization & 13 & $50.0 \%$ & 13 & $50.0 \%$ & & & & & & & & & 26 & $11.6 \%$ \\
\hline (6) Curricular adaptation to educational needs & 12 & $22.6 \%$ & 12 & $22.6 \%$ & 9 & $17.0 \%$ & 6 & $11.3 \%$ & 14 & $26.4 \%$ & & & 53 & $9.5 \%$ \\
\hline (7) Social features & 8 & $20.5 \%$ & 10 & $25.6 \%$ & 14 & $35.9 \%$ & 7 & $17.9 \%$ & & & & & 39 & $8.7 \%$ \\
\hline (8) Global features of motor skills games & 16 & $50.0 \%$ & 16 & $50.0 \%$ & & & & & & & & & 32 & $14.3 \%$ \\
\hline (9) Specific features of motor skills games & 3 & $33.3 \%$ & 6 & $66.7 \%$ & & & & & & & & & 9 & $4.0 \%$ \\
\hline (10) Body language games and assessment & 10 & $27.0 \%$ & 1 & $2.7 \%$ & 2 & $5.4 \%$ & 3 & $8.1 \%$ & 1 & $2.7 \%$ & 20 & $54.1 \%$ & 37 & $5.5 \%$ \\
\hline
\end{tabular}

${ }^{\mathrm{a}}$ Total percentage was normalized to compare results between categories.

is crucial in PE, as it offers endless sources for sessions and increases participation.

"There were two drills, and it was like they were pirates on a boat. They used hoops, zigzag cones, balls, ropes. . . It was like a river. There were stones, and they had to go over them without falling. . . . Then, they threw balls into hoops, crept through mats, wore headscarves . . ."(C10, Ref. 1)

\section{Data Transformation Analysis (Qualitative Data Quantitatively Expressed)}

This section displays a frequency analysis of the excerpts from the analyzed interviews, counting the number of citations related to the categories and aspects of the TC/MSBLG-R. In addition, the percentage value of each category and aspect was also calculated. This data transformation was previously used on studies referring to PE teacher education (Gil-Gómez et al., 2015). However, in this study, the procedure was performed in three different levels: globally, showing the number of excerpts per category in each interview (Table 1); by aspects, indicating the frequency of citations into each specific category (Table 2); and by interviews, presenting all of the records related to each interview individually (Table 3).

\section{Discussion}

Globally, the results obtained in the quantitative analysis indicated that both experimental groups improved their TC in the PE area. Although the results for EGI were slightly higher than those of EGII, the posttest results revealed no statistical differences between them. However, qualitative analysis showed an enormous academic impact on the EGI PTs for all study sections. Similarly, the data transformation reinforced this global assessment, as it showed nearly 4,000 excerpts that referred to the $\mathrm{TC}$ in the analyzed interviews. Altogether, the data revealed outstanding academic progress of the PTs due to their participation in the SL program, agreeing with prior theoretical work concerning the impact of SL in education (Chambers \& Lavery, 2012; Seban, 2013), as well as with several meta-analyses regarding the effects of SL (Celio et al., 2011; Conway et al., 2009; Yorio \& Ye, 2012). In addition, as there are no statistical differences between the posttest measures of either group, new proposals of intervention with greater differences between modalities should be analyzed in future research.

Moreover, the category-by-category analysis supported these global findings. The quantitative study revealed that EGI improved in six out of 10 categories of the TC/MSBLG-R, whereas EGII improved in five categories. The categories of teacher organization 
and game adjustment; game presentation and rule compliance; equipment, originality, and ludic value; time organization and game variety; space organization; and global features of motor skills games presented high scores in quantitative and data transformation analysis. The qualitative study complemented this perspective, explaining how the PTs increased their confidence to design and apply games in the PE sessions. This situation points out that the greatest result of SL implementation with PE PTs was focused in gaining basic skills for effective teaching (Galvan \& Parker, 2011). On the other hand, the results referring to curricular adaptation to educational needs, social features, specific features of motor skills games, and body language games and assessment were less prominent in both quantitative and data transformation analyses. A similar evolution was shown in the qualitative study, suggesting that these categories showed a more modest development through SL. Hence, it is necessary to pay more attention to promoting these outcomes in future SL interventions in PE. Finally, there were many correlations among the TC/MSBLG-R categories, evidencing a strong relationship among the academic elements analyzed.

Altogether, this study reveals an enormous impact on PTs' academic learning, especially in terms of combining theory and practice (Wilkinson et al., 2013). In addition, the results from the different analyses performed presented highly coincidental and complementary data. This situation indicates that the SL program had a very similar effect among the PTs in this study. Next, the main results obtained referring to the categories and aspects of the TC/MSBLG-R are discussed.

The first category refers to teacher organization and game adjustment. The quantitative analysis showed outstanding results for the activities adjusted to children's age and course period, as aspects of this category, as well as for promoting active participation. The qualitative findings suggest an enhanced capacity of PTs to analyze and manage information to complete their tasks as teachers (Osborne, Hammerich, \& Hensley, 1998). Particularly, remarkable improvements were obtained in stimulating the children's interest and motivation (Baldwin, Buchanan, \& Rudisill, 2007; LaMaster, 2001) and applying risk-free activities (Domangue \& Carson, 2008).

The game presentation and rule compliance results agree in highlighting the description of activities as the best aspect, pointing to a greater fluency and efficacy in explaining tasks (Massey-Stokes \& Meaney, 2006; Meaney et al., 2008; Miller, 2012). The qualitative analysis showed remarkable progress in the implementation of the rules (Himelein, Passman, \& Phillips, 2010) and the management of the children's behavior (Domangue \& Carson, 2008; Meaney et al., 2009; Robinson \& Meyer, 2012), focusing on the improvement of rules understanding and control of compliance rules. In addition, an appropriate development in applying the standards and protocols of PE was also highlighted (LaMaster, 2001).

The equipment, originality, and ludic value category presented modest scores. However, it showed a good increase in the management and organization competencies (Yorio \& Ye, 2012) related to equipment resources. This situation is also linked to activity development, task management, self-efficacy, improvisation, and problem solving (Himelein et al., 2010; Meaney et al., 2009). Finally, the advancement in equipment optimization described a useful resource when working with limited equipment (Pechak \& Thompson, 2011).

Aspects from the space organization and time organization and game variety categories displayed remarkable results for the quantitative and data transformation analyses. In addition, the qualitative research revealed a strong relationship between both categories due to the improvement in management and organization competences (Yorio \& Ye, 2012) related to space and time issues, respectively.

The curricular adaptation to educational needs category presented modest results in the quantitative analysis. However, the qualitative analysis revealed an improvement in paying attention to the specific needs of children with motor functional diversity (Galvan \& Parker, 2011). Similarly, an enhancement of achieving additional curriculum goals was also highlighted (Baldwin et al., 2007; Galvan et al., 2018).

Aspects from the social features category obtained nonremarkable values in both the quantitative and data transformation studies. On the other hand, the qualitative analysis described experiences related to diversity, inclusion, solidarity, educational and social features, values of social justice, and personal and social growth. The promotion of these qualities was also shown in previous studies performed in different areas of the United States (Baldwin et al., 2007; Miller, 2012), suggesting that those effects may appear independently of the social context. Finally, the management of children's competitive behaviors represents another crucial learning opportunity for teaching in PE (Domangue \& Carson, 2008).

The results related to global features of motor skills games were the most significant for both the quantitative and data transformation analyses. On the other hand, the categories of specific features of motor skills games and body language games and assessment obtained modest scores for all quantitative data. Similarly, although the qualitative results displayed an improvement of the global features, based on the quality from the motor games used, it was more difficult to promote specific coordination and, particularly, fine motor skills. As such, this situation could be explored in future SL implementations. The findings from these categories offer a new benchmark on this research topic, as no similar results have been found in a literature search of previous studies. Finally, the qualitative analysis also revealed that activities assessment was improved due to progress in critical and reflexive thinking (Pechak \& Thompson, 2011).

In the next section, the most relevant additional outcomes, also extracted from the qualitative interviews, are discussed. First, the experience provided "in the field" is highlighted. This represents one of the leading effects of SL, allowing investigators to apply action research and reflection processes in real teaching contexts (Baldwin et al., 2007; Bishop \& Driver, 2007; Robinson \& Meyer, 2012). In addition, using new teaching strategies, interacting with the children's parents, applying new proposals, and practicing in different contexts also resulted in outstanding learning outcomes for PTs (Domangue \& Carson, 2008; Massey-Stokes \& Meaney, 2006). Similarly, the PTs explained that working with this group of children fostered the learning process due to adjusting activities to their individual needs (Bishop \& Driver, 2007). The PTs also emphasized that independent tasks increased their global competencies as a result of not being under the professor's direct supervision (Domangue \& Carson, 2008). Other remarkable observations refer to the reciprocal learning promoted between the PTs and service recipients and the development of several teaching skills through this pedagogical practice (Baldwin et al., 2007; Miller, 2012).

\section{Conclusion}

The approach of mixed methods, using methodological triangulation, offers a great opportunity to analyze the promotion of TC on the 
PTs in PE. Indeed, highly reinforcing and complementary records have emerged among the different results observed in this study. From this data, it is evidenced that SL fostered the TC of the PTs in PE, signifying an educational experience with great academic value. In addition, the qualitative results offer valuable information to help researchers understand how these learning outcomes were achieved. Moreover, the relationship between the analyzed elements shows their mutual reinforcement. Finally, the social and civic aspects developed represent an added benefit.

Therefore, the $\mathrm{H}_{1}$ and $\mathrm{H}_{2}$ hypotheses are accepted, as there are significant improvements $(p<.01)$ in the TC/MSBLG-R results for EGI and EGII, respectively. On the other hand, the $\mathrm{H}_{3}$ hypothesis is rejected, as there is no significant difference $(p<.05)$ in the TC/MSBLG-R results for EGI compared with EGII. Meanwhile, the depth of experience and insight demonstrated by the PTs, in terms of increasing their TC in PE, offers a broader answer to the research question.

In conclusion, the SL program produced outstanding improvements in the TC of the PTs in PE. This conclusion agrees with most theoretical work about SL and reviews of the literature, as well as previous studies regarding the effects of this methodology in teaching PE. Also, the study displays new outcomes concerning the specific impact of SL, especially in designing and applying sessions of motor skills and body language games. Finally, it demonstrates that the implementation of the SL program, in both modalities of intervention, stimulates academic learning and several social aspects with remarkable educational interest.

Regarding future research, it would be necessary to contrast the SL modalities with greater differences in terms of duration and intensity. Similarly, it would be promising to open research lines that analyze the effects of SL on service recipients and community members, and to study the impact of this methodology throughout the entire teaching-learning process, analyzing its long-term effects on students, recipients, and society.

\section{Acknowledgments}

The authors thank the NIH Library Writing Center for manuscript editing assistance. This work was supported by the Universitat Jaume I under Grant UJI-A2017-03.

\section{References}

Baldwin, S.C., Buchanan, A.M., \& Rudisill, M.E. (2007). What teacher candidates learned about diversity, social justice, and themselves from service-learning experiences. Journal of Teacher Education, 58(4), 315-327. doi:10.1177/0022487107305259

Bishop, J., \& Driver, S. (2007). Implementing service-learning in undergraduate adapted physical education. Journal of Physical Education, Recreation \& Dance, 78(8), 15-19. doi:10.1080/07303084.2007. 10598071

Camerino, O., Castañer, M., \& Anguera, M.T. (Eds.). (2012). Mixed methods research in the movement sciences. Case studies in sport, physical education and dance. New York, NY: Routledge.

Capella-Peris, C., Gil-Gómez, J., \& Chiva-Bartoll, Ò. (2018). A rubric to assess the teaching competency using motor skills and body language games: Initial development and validation. Journal of Physical Education and Sport, 18(2), 944-954. doi:10.7752/jpes.2018.02140

Carson, R.L., \& Raguse, A.L. (2014). Systematic review of servicelearning in youth physical activity settings. Quest, 66(1), 57-95. doi:10.1080/00336297.2013.814578
Celio, C.I., Durlak, J., \& Dymnicki, A. (2011). A meta-analysis of the impact of service-learning on students. Journal of Experiential Education, 34(2), 164-181. doi:10.1177/105382591103400205

Cervantes, C.M., \& Meaney, K.S. (2013). Examining service-learning literature in physical education teacher education: Recommendations for practice and research. Quest, 65(3), 332-353. doi:10.1080/ 00336297.2013.773533

Chambers, D.J., \& Lavery, S. (2012). Service-learning: A valuable component of pre-service teacher education. Australian Journal of Teacher Education, 37(4), 128-137. doi:10.14221/ajte.2012v37n4.2

Conway, J.M., Amel, E.L., \& Gerwien, D.P. (2009). Teaching and learning in the social context: A meta-analysis of service learning's effects on academic, personal, social, and citizenship outcomes. Teaching of Psychology, 36(4), 233-245. doi:10.1080/ 00986280903172969

Creswell, J.W., \& Plano Clark, V.L. (2007). Designing and conducting mixed methods research. Thousand Oaks, CA: Sage Publications.

Cronbach, L.J., \& Meehl, P.E. (1955). Construct validity in psychological tests. Psychological Bulletin, 52(4), 281-302. PubMed ID: 13245896 doi:10.1037/h0040957

Demazière, D., \& Dubar, C. (1997). Analyser les entretiens biographiques. L'exemple des récits d'insertion. Paris, France: Éditions Nathan.

Denzin, N.K. (1989). Interpretive biography (qualitative research methods). Newbury Park, CA: Sage Publications.

Dewey, J. (1938). Experience and education. New York, NY: Macmillan.

Domangue, E., \& Carson, R.L. (2008). Preparing culturally competent teachers: Service-learning and physical education teacher education. Journal of Teaching in Physical Education, 27(3), 347-367. doi:10. $1123 /$ jtpe.27.3.347

Flick, U. (2014). An introduction to qualitative research (5th ed.). Thousand Oaks, CA: Sage Publications.

Galvan, C., Meaney, K., \& Gray, V. (2018). Examining the reciprocal nature of service-learning for underserved students and preservice teachers. Journal of Teaching in Physical Education, 37(4), 363-372. doi:10.1123/jtpe.2018-0051

Galvan, C., \& Parker, M. (2011). Investigating the reciprocal nature of service-learning in physical education teacher education. Journal of Experiential Education, 34(1), 55-70. doi:10.1177/ 105382591103400105

Gil-Gómez, J., Chiva-Bartoll, Ò., \& Marti-Puig, M. (2015). The impact of service learning on the training of pre-service teachers: Analysis from a physical education subject. European Physical Education Review, 21(4), 467-484. doi:10.1177/1356336X15582358

Hernández, F., Sancho, J.M., \& Rivas, J.I. (2011). Historias de vida en educación. Biografías en contexto. Barcelona, Spain: ESBRINA RECERCA/Universitat de Barcelona.

Himelein, M., Passman, L., \& Phillips, J.M. (2010). College teaching and community outreaching: Service learning in an obesity prevention program. American Journal of Health Education, 41(6), 368-378. doi:10.1080/19325037.2010.10599166

Jones, A.L., \& Kiser, P.M. (2014). Conceptualizing criticality as a guiding principle for high quality academic service learning. International Journal of Teaching and Learning in Higher Education, 26(1), 147-156.

Lake, V.E., Al Otaiba, S., \& Guidry, L. (2010). Developing social skills training and literacy instruction pedagogy through service learning: An integrated model of teacher preparation. Journal of Early Childhood Teacher Education, 31(4), 373-390. doi:10.1080/10901027. 2010.523776

Lake, V.E., \& Jones, I. (2008). Service-learning in early childhood teacher education: Using service to put meaning back into learning. Teaching and Teacher Education, 24(8), 2146-2156. doi:10.1016/j.tate.2008. 05.003 
LaMaster, K.J. (2001). Enhancing preservice teachers field experiences through the addition of a service-learning component. Journal of Experiential Education, 24(1), 27-33. doi:10.1177/ 105382590102400107

Massey-Stokes, M., \& Meaney, K.S. (2006). Understanding our servicelearning community: An exploratory study of parent, teacher and student perceptions about childhood obesity. The Health Educator, 38(2), 53-60.

Meaney, K.S., Bohler, H.R., Kopf, K., Hernandez, L., \& Scott, L.S. (2008). Service-learning and pre-service educators' cultural competence for teaching: An exploratory study. Journal of Experiential Education, 31(2), 189-208. doi:10.1177/105382590803100206

Meaney, K.S., Griffin, K., \& Bohler, H. (2009). Service-learning: A venue for enhancing pre-service educators' knowledge base for teaching. International Journal for the Scholarship of Teaching and Learning, 3(2), 19. Article 21. doi:10.20429/ijsotl.2009.030221

Miller, M. (2012). The role of service-learning to promote early childhood physical education while examining its influence upon the vocational call to teach. Physical Education and Sport Pedagogy, 17(1), 61-77. doi:10.1080/17408981003712810

Mitchell, T.D. (2008). Traditional vs critical service learning: Engaging the literature to differentiate two models. Michigan Journal of Community Service Learning, 14(2), 50-65.

National Youth Leadership Council. (2004). Growing to greatness 2004. The state of service-learning project. Saint Paul, MN: State Farm Companies Foundation.

Osborne, R.E., Hammerich, S., \& Hensley, C. (1998). Student effects of service-learning: Tracking change across a semester. Michigan Journal of Community Service Learning, 5(1), 5-13.

Pamphilon, B. (1999). The zoom model: A dynamic framework for the analysis of life histories. Qualitative Inquiry, 5(3), 393-410. doi:10. 1177/107780049900500306

Pechak, C., \& Thompson, M. (2011). Going global in physical therapist education: International service-learning in US-based programmes. Physiotherapy Research International, 16(4), 225-236. PubMed ID: 21136587 doi:10.1002/pri.501
Robinson, D.B., \& Meyer, M. (2012). Health education and interactive drama: Findings from a service learning project. Health Education Journal, 71(2), 219-228. doi:10.1177/0017896911398811

Seban, D. (2013). The impact of the type of projects on preservice teachers' conceptualization of service learning. Teaching and Teacher Education, 32, 87-97. doi:10.1016/j.tate.2013.01.009

Sparkes, A.C., Templin, T.J., \& Schempp, P.G. (1993). Exploring dimensions of marginality: Reflecting on the life histories of physical education teachers. Journal of Teaching in Physical Education, 12(4), 386-398. doi:10.1123/jtpe.12.4.386

Ward, S., Pellett, H.H., \& Perez, M.I. (2017). Cognitive disequilibrium and service-learning in physical education teacher education: Perceptions of pre-service teachers in a study abroad experience. Journal of Teaching in Physical Education, 36(1), 70-82. doi:10.1123/jtpe. 2015-0006

Webster, C.A., Nesbitt, D., Lee, H., \& Egan, C. (2017). Preservice physical education teachers' service learning experiences related to comprehensive school physical activity programming. Journal of Teaching in Physical Education, 36(4), 430-444. doi:10.1123/jtpe. 2016-0191

White, A.E. (2001). A meta-analysis of service learning research in middle and high schools (Doctoral dissertation). University of North Texas, Denton, TX. Retrieved from https://digitalcommons.unomaha.edu/ cgi/viewcontent.cgi?article $=1050 \&$ context $=$ slcedt

Whitley, M.A., Walsh, D., Hayden, L., \& Gould, D. (2017). Narratives of experiential learning: Students' engagement in a physical activitybased service-learning course. Journal of Teaching in Physical Education, 36(4), 419-429. doi:10.1123/jtpe.2016-0141

Wilkinson, S., Harvey, W.J., Bloom, G.A., Joober, R., \& Grizenko, N. (2013). Student teacher experiences in a service-learning project for children with attention-deficit hyperactivity disorder. Physical Education and Sport Pedagogy, 18(5), 475-491. doi:10.1080/17408989. 2012.690385

Yorio, P.L., \& Ye, F. (2012). A meta-analysis on the effects of servicelearning on the social, personal, and cognitive outcomes of learning. Academy of Management Learning \& Education, 11(1), 9-27. doi:10. 5465/amle.2010.0072 